\title{
Mechanical pretreatment for increased biogas production from lignocellulosic biomass; predicting the methane yield from structural plant components
}

\author{
Tsapekos, Panagiotis; Kougias, Panagiotis ; Angelidaki, Irini
}

Published in:

Waste Management

Link to article, DOI:

10.1016/j.wasman.2018.07.017

Publication date:

2018

Document Version

Peer reviewed version

Link back to DTU Orbit

Citation $(A P A)$ :

Tsapekos, P., Kougias, P., \& Angelidaki, I. (2018). Mechanical pretreatment for increased biogas production from lignocellulosic biomass; predicting the methane yield from structural plant components. Waste Management, 78, 903-910. https://doi.org/10.1016/j.wasman.2018.07.017

\section{General rights}

Copyright and moral rights for the publications made accessible in the public portal are retained by the authors and/or other copyright owners and it is a condition of accessing publications that users recognise and abide by the legal requirements associated with these rights.

- Users may download and print one copy of any publication from the public portal for the purpose of private study or research.

- You may not further distribute the material or use it for any profit-making activity or commercial gain

- You may freely distribute the URL identifying the publication in the public portal 
6

9

$10{ }^{*}$ Corresponding author: Panagiotis G. Kougias, Department of Environmental

11 Engineering, Technical University of Denmark, Bld 113, 2800 Lyngby, Denmark.

12 E-mail address: panak@env.dtu.dk, Tel.: +45 45251454 


\section{Abstract}

14 Lignocellulosic substrates are associated with limited biodegradability due to the 15 structural complexity. For that reason, a pretreatment step is mandatory for efficient 16 biomass transformation which will lead to increased bioenergy output. The aim of the

17 present study was to assess the efficiency of two pretreatment machines to enhance the

18 methane yield of meadow grass. Specifically, the application of shearing forces with a

19 rotated plastic sweeping brush against a steel roller significantly increased biomass

20 biodegradability by $20 \%$ under relatively gentle operation conditions (600 rpm). The

21 more intense operation (1200 rpm) was not associated with higher methane yield

22 enhancement. Regarding an alternative machine, in which the brush was replaced with a

23 coarse steel roller resulted in a more distinct effect $(+27 \%)$ despite the lower rotating

24 speed ( 400 rpm). Moreover, the association of the substrate's individual chemical

25 components and the practical methane yield was assessed, establishing single and

26 multiple linear regression models. However, the estimation accuracy was rather low

27 with either single (regressor: lignin, $R^{2}: 0.50$ ) or multiple linear regression analyses

28 (regressors: arabinan-lignin-protein, $R^{2}: 0.61$ ). Results showed that poorly lignified

29 plant tissue containing relatively high fractions of protein and arabinan is more

30 susceptible to anaerobic digestion.

\section{Keywords}

33 Biogas; Mechanical pretreatment; Methane yield; BMP prediction model; Principal

34 component analysis 


\section{Introduction}

Agricultural land (i.e. arable land, permanent crops, permanent meadows and pastures) covers more than $37 \%$ of the total land surface with lignocellulosic biomass as the main organic component (Faostat, 2016). Lignocellulosic biomass is considered as a potential feedstock for industrial biofuels production (e.g. biogas, bioethanol). This application has several advantages, e.g. besides of being $\mathrm{CO}_{2}$ neutral, it is contributing to lower emissions compared to the common practice of burning the lignocellulosic residues on the field (Hayashi et al., 2014; Marañón et al., 2011). Among the different technologies for biofuel production using lignocellulosic materials, anaerobic digestion appears as the most promising application as it is more energetically favourable compared to liquid biofuels (Frigon and Guiot, 2010).

The biomass' characteristics, such as plant size, shape and moisture content are crucial for efficient biomethanation and also, optimal process performance. Thus, lignocellulosic materials need to be pretreated prior to their introduction in the anaerobic reactor in order to avoid operational problems (e.g. clogging, floating layers) (Mönch-Tegeder et al., 2014). Moreover, the pretreatment is essential in order to minimise the resistance of the solid feedstocks to enzymatic attack. Indeed, it is mandatory to disrupt the complex lignocellulosic structure in order to improve the conversion of structural carbohydrates to monomeric sugars (Katukuri et al., 2017; Ranjan and Moholkar, 2013). On this topic, it was recently shown that mechanical comminution machines can efficiently improve the biomass characteristics for biogas applications (i.e. size reduction, surface disruption, partial drying) (Tsapekos et al., 2017a). In general, mechanical pretreatments are considered more appropriate for industrial applications compared to the alternative methods (i.e. thermal, chemical, 
60 biological) (Carrere et al., 2015). The mode of action of mechanical methods relies on the application of shear and/or compression forces to boost biomass deconstruction (Kratky and Jirout, 2011). With respect to operational features, the selection of suitable construction materials is of major importance. Indeed, it was reported that using materials of high coarseness to equip a comminution device, the biogas enhancement could be significantly improved compared to other smoother materials (Tsapekos et al., 2015).

Moreover, for the overall sustainability of the pretreatment method, durability and robustness of equipment is of high importance. For instance, the performance of equipment can be deteriorated in real-life applications and in cases that large materials other than biomass are processed in error (e.g. metal pieces or stones). Thus, machine's lifetime can be markedly decreased or the equipment can collapse adding extra costs. In this context, the controlled and optimized operation of full-scale harvesting machines can remarkably reduce the energy input and in parallel, increase the output of lignocellulose-based AD (Tsapekos et al., 2017). Likewise, it was revealed that the energy balance of $\mathrm{AD}$ using various crops is significantly affected by the performance of the used comminution machine (Herrmann et al., 2012). Hence, both a careful design of equipment in terms of materials and technology and also, the proper usage should always be ensured in order to efficiently apply vigorous mechanical forces and consequently, increase substrate's biodegradability.

80 Of equal importance with pretreatment's efficiency for high bioenergy output are 81 the feedstock's characteristics. For instance, biomass biodegradability is negatively correlated to the level of cell walls lignification (Wang et al., 2009). In contrast, ensiled substrates are possibly associated with high methane production due to the fermentation 
84 of complex carbohydrates into metabolic intermediates (e.g. lactic acid) that took place during the ensiling process (Vervaeren et al., 2010). Despite well-established knowledge about the relations of biomass characteristics and biodegradability, a standardised and constant correlation between chemical characteristics and biochemical methane potential (BMP) is not yet existing (Dandikas et al., 2015). In addition, the BMP measurement provides important information about substrate's biodegradability but it is a time-demanding process (Charnier et al., 2016). Conversely, the analytical methods for biomass characterization are only requiring relatively short time. Hence, linking prompt methods with the BMP values could establish a fast decision-making tool in order to design and apply strategies that can lead to process optimisation in fullscale applications (Fitamo et al., 2017). In a recent study, more than 200 samples were used to correlate the hydrolysis rate constant with the chemical composition of different biomasses, as a precursor for predicting the biogas production (Dandikas et al., 2018). The non-fibre structural sugars and crude protein contents were associated with the most efficient, but still moderate, prediction accuracy $\left(R^{2} \sim 66 \%\right)$. Thus, the suggested approach can be followed for an initial assessment of feedstock degradation potential; however, a strong correlation that leads to accurate forecasting cannot be expected.

101 Similarly, Edwiges et al. (2018) examined the correlation between the compositional 102 components of fruit-vegetable residues and methane potential. Results interpretation 103 revealed that lignin content is a strong predictor of solid waste, which is in accordance

104 with a similar previous study (Triolo et al., 2011). However, lignin is significantly higher at agricultural residues compared to the fruit-vegetable waste, and additionally,

106 its chemical structure differs markedly among the various lignocellulosic species.

107 Moreover, lignocellulose characteristics, such as crystallinity, degree of polymerization, 
108 content and composition of monolignol precursors, can indirectly affect the anaerobic

109 biodegradability. Hence, linking the chemical synthesis with the practical methane yield

110 is still challenging.

111 The present study aims to elucidate the efficiency of two mechanical pretreatment

112 methods for enhancing the biogas production from meadow grass. The performance was

113 evaluated with respect to different operational parameters (i.e. different rotating speeds

114 and biomass loads). Meadow grass was used a model biomass for the pretreatment tests

115 due to its high availability in marginal lands and environmentally sensitive areas.

116 Specifically, the meadow grass that is not used for grazing during summer due to its low

117 fodder value can with great benefit be exploited for bioenergy purposes. Moreover, the

118 correlation among substrate's chemical characteristics and methane yield was examined

119 to develop a rapid and reliable model to predict lignocellulose's biodegradability. The

120 development of an efficient prediction tool could allow the biogas plant operators to

121 successfully assess the energy output that can be obtained by a given substrate. This

122 application signifies, its high importance for real-life practices. On this subject, a

123 heterogeneous dataset using various agricultural substrates were used to develop a

124 prediction model.

125

126 2. Materials and methods

127 2.1. Inoculum

128 Inoculum was obtained from the effluent tank of a thermophilic biogas plant

129 (Snertinge, Denmark). The inoculum was immediately transported to the laboratory and

130 subsequently, was sieved to remove particles larger than $10 \mathrm{~mm}$. Afterwards, the

131 inoculum was incubated for 10 days at thermophilic temperature to remove background 
132 methane production. The main chemical characteristics of the inoculum were: $\mathrm{pH}: 8.07$,

133 Total Solids (TS): $24.1 \pm 0.1 \mathrm{~g} / \mathrm{L}$, Volatile Solids (VS): $15.0 \pm 0.1 \mathrm{~g} / \mathrm{L}$, Total Kjeldahl

134 Nitrogen (TKN): $4.6 \pm 0.2$ g-TKN/L, Ammonium Nitrogen: $3.8 \pm 0.1 \mathrm{~g} \mathrm{NH}_{4}^{+}-\mathrm{N} / \mathrm{L}$, and 135 total Volatile Fatty Acids (TVFA): $0.7 \pm 0.1 \mathrm{~g} / \mathrm{L}$.

\subsection{Substrates}

To define the correlation between methane production and lignocellulosic substrates' chemical composition, diverse species were examined; grass obtained from

140 various meadows (i.e. M1-M7), grass clippings (GC), wheat straw (WS) and digested

141 biofibers (DB). Samples of non-cultivated meadow grass were manually collected from

142 natural grasslands. The meadow fields were mainly consisted of white clover, tetraploid

143 hybrid ryegrass, diploid early perennial ryegrass and diploid medium-early perennial

144 ryegrass. For proper silage fermentation, the grasses were kept intact at room

145 temperature for two days to be partially dried, and then, were placed in anaerobically

146 sealed plastic bags without injecting biological additives for sixty days. Grass clippings

147 and wheat straw were collected from fields in Zealand, Denmark. Overall, ten different

148 lignocellulosic substrates were examined in triplicate samples. The chemical

149 composition of the used substrates is presented in Table 1. Samples were ground to 2

$150 \mathrm{~mm}$ to determine their chemical characteristics.

\subsection{Mechanical pretreatment}

153 Meadow grass was used in order to assess the efficiency of mechanical

154 pretreatments on biogas enhancement (Table 2). Two different mechanical pretreatment

155 units were constructed in order to evaluate their effect on the anaerobic biodegradability 
156 of meadow grass. The first machine was consisted of a road sweeping brush and a steel

157 mesh conditioner (crimper) (Fig. 1a). Pretreatment's efficiency was based on the

158 principle that the plastic brush roller, which was placed diametrically opposed to the

159 steel roller can intensively press the biomass towards the reversely rotating equipment.

160 The brush roller was rotated at different driving speeds in order to define the most

161 optimal operation (Table 2). Conversely, the steel roller was always rotating in the same

162 speed as its main usage was to ensure a proper grass flow towards the brush roller.

163 During all trials, the same amount of grass $\left(1.4 \mathrm{~kg} / \mathrm{m}^{2}\right)$ was treated to simulate the

164 application of a full-scale harvester at a typical meadow field. Regarding the second

165 test, the comminuting apparatus was partially amended in order to enhance the damage

166 of biomass surface. Hence, a corrugated roller with coarse steel surface was rotating

167 towards a stable coarse shell (Fig. 1b). Additionally, different amounts of grass were

168 pretreated in order to operate the unit at different biomass loads. During both tests, the

169 grass was placed on a conveyor belt, which supplied the biomass to the pretreatment

170 units. In order to simulate the procedure in full-scale, the conveyor was operated at the

171 same driving speed of a mower at a real field $(10 \mathrm{~km} / \mathrm{h})$.

172

\subsection{Batch experiments}

174 Batch assays were conducted to determine the Biochemical Methane Potential

175 (BMP) of untreated and pretreated substrates according to the guidelines described by

176 (Angelidaki et al., 2009). Glass bottles of $547 \mathrm{~mL}$ total volume were employed and

177 filled with specific amounts of water, inoculum and substrate to reach working volume

178 of $200 \mathrm{~mL}$ and initial organic load of $2 \mathrm{gVS} / \mathrm{L}$. The inoculum consisted $80 \%(\mathrm{v} / \mathrm{v})$ of the

179 working volume to ensure that the volume of microbial biomass was sufficient enough 
180 to efficiently digest the organic matter. Thus, the batch assays were set-up at inoculum

181 to substrate ratio equal to 8 . The adjustment of the initial organic load targeted given

182 value was performed by supplementing the batch vials with water. The inoculum

183 content was always kept constant. The reactors were flushed with $100 \% \mathrm{~N}_{2}$ to ensure

184 anaerobic conditions and subsequently, placed in thermophilic incubator $\left(54 \pm 1{ }^{\circ} \mathrm{C}\right)$.

185 Manual mixing of the batch reactors and gas measurements were conducted in a regular 186 basis until cease of methane production $(p<0.05)$.

\subsection{Analytical methods}

Measurements of TS, VS, $\mathrm{pH}, \mathrm{NH}_{4}^{+}-\mathrm{N}$ and protein were performed according to the standard methods for the examination of water and wastewater (APHA, 2005).

191 Structural carbohydrates (i.e. glucan, xylan, arabinan) and Klason lignin were measured 192 according to (Sluiter et al., 2011). The quantification of carbohydrates was performed

193 using Ion chromatography (Dionex ICS-5000, Thermo Scientific).An analytical column

194 (CarboPak PA1, $250 \times 4 \mathrm{~mm}$ ) was employed for sugars separation using 100\% Milli-Q water as first eluent, $1 \mathrm{M} \mathrm{NaOH}$ as second eluent and $100 \mathrm{mM} \mathrm{NaOH}$ as third eluent; at a constant flow rate of $1.0 \mathrm{~mL} / \mathrm{min}$. Gas chromatography (Shimadzu GC-8A, Japan) was used to determine the BMP of the lignocellulosic substrates and the volatile fatty acids

198 (VFA) composition of the inoculum (Kougias et al., 2015). The carbon to nitrogen ratio 199 (C:N) of lignocellulosic substrates was defined using a vario MACRO cube, CHNOS elemental analyzer (Hanau, Germany). All the physicochemical analyses were conducted in triplicate samples. Scanning Electron Microscopy (SEM) images were taken using a FEI Quanta 200 F equipped with a Field Emission Gun (FEG) to illustrate

203 the damages on the grass morphology provoked by the comminution machines. Freeze 
dried lignocellulosic biomasses were placed onto aluminium SEM specimen stubs with carbon conductive tabs and coated with gold for higher conductivity.

\subsection{Data analysis}

$$
\text { The effect of mechanical pretreatments on the kinetics of grass anaerobic }
$$

degradation was evaluated using the modified Gompertz equation:

$$
M(t)=M_{0} \times \exp \left\{-\exp \left[\frac{R_{\max } \times e}{M_{0}}(\lambda-t)+1\right]\right\}
$$

211 where:

$212 M(t)=$ accumulated $\mathrm{CH}_{4}$ yield at digestion time $t\left(\mathrm{mLCH}_{4} / \mathrm{gVS}\right)$,

$213 \quad M_{0}=\mathrm{CH}_{4}$ yield $(\mathrm{mL} / \mathrm{gVS})$,

$214 R_{\max }=$ maximum $\mathrm{CH}_{4}$ production rate $(\mathrm{mL} / \mathrm{gVS} / \mathrm{d})$,

$215 \lambda=$ lag phase (day),

$216 \quad e=$ Euler's constant (2.7183).

217 The coefficient of determination $\left(R^{2}\right)$ and the root mean square error (RMSE) were

218 calculated in order to evaluate the prediction accuracy of the models (Tsapekos et al.,

219 2015). Tukey post hoc test $(p<0.05)$ and one-way analysis of variance (ANOVA) was

220 followed to define any statistically significant differences among untreated and

221 pretreated samples using the software Graphpad Prism (Graphpad Software, Inc., San

222 Diego, CA). The Kolmogorov-Smirnov test was applied $(p<0.05)$ to determine the

223 normal distribution of the samples. Descriptive statistics and principal component

224 analysis (PCA) were performed to examine the correlations among chemical

225 characteristics. Moreover, multiple linear regression analysis was conducted in order to 226 predict the methane yield of lignocellulosic substrates. To define the prediction accuracy, the coefficient of variation $(\mathrm{CV})$ and normalised root mean square error 

was used for the analysis.

\section{Results and discussion}

\subsection{BMP experiments}

The methane yields of untreated and pretreated grass with both pretreatment units are summarized in Table 2. Regarding the first pretreatment unit, the most profound enhancement $(20 \%, p<0.05)$ was achieved at the moderate rotating conditions (600 rpm) (Fig. 2a). Apart from the most optimal operation, no significant differences ( $p>$

237 0.05) were observed for the rest trials in comparison with untreated operation.

238 Moreover, the highest rotating speeds (i.e. 900 and $1200 \mathrm{rpm}$ ) had similar effect $(p>$ 239 0.05) on biomethanation compared to the smoothest operation (i.e. $200 \mathrm{rpm}$ ). This result

240 is contradictory with a previous study in which grass biodegradability was

241 proportionally related to the increased harvesting speed of full-scale machines

242 (Tsapekos et al., 2017).The efficiency of pretreatment units is not always directly

243 correlated with the rotational speed. It is mainly the disruption technology that highly

244 influences the level of plant's structural disruption (Kratky and Jirout, 2011) and at a

245 lesser extent, the rotational speed. In this context, Boscaro et al. (2015) suggested that

246 flail or disc mowing are appropriate solutions for extracting grass from the fields to

247 supply AD plants. Flail or disc mowers are based on rotating horizontal drums which 248 are similar to the constructed pretreatment unit.

249 In the present study, the grass flow through the rollers could be improved at 250 moderate rotating speed avoiding blockage of the equipment and thus, the demanding 251 shearing forces were more efficiently applied. Apart from the increments on methane 
252 yield, the kinetic parameters were also influenced during pretreatment trials (Table 2).

253 Specifically, the examined methods insignificantly $(p>0.05)$ decreased the lag phase of

254 pretreated samples according to the modified Gompertz model. The results are in

255 accordance with a previous research, in which the performance of full-scale machines

256 on mechanical disruption was evaluated demonstrating that the utilisation of the most

257 efficient machinery led to a reduction of digestion's lag phase (Tsapekos et al., 2017a).

258 Actually, during the AD of lignocellulosic biomass, lag phase is typically detected due

259 to high structural complexity of these substrates. Hence, a model that takes into account

260 this acclimation period is considered to be appropriate for parameter's estimation (Kafle

261 and Chen, 2016). In this context, the good fit of the model was observed by the high $R^{2}$

262 and low RMSE values and thus, reliable prediction accuracy was concluded (Raju et al.,

263 2011). Moreover, the methane production rates were only slightly improved $(p>0.05)$

264 in the majority of the pretreated samples.

265 As a continuation of the first AD trial, a consecutive BMP test was conducted in

266 order to examine the effect of a modified version of the machine on the biodegradability

267 of lignocellulosic biomass. Specifically, the plastic brush roller was replaced by a coarse

268 corrugated roller. The modifications were conducted based on previous findings which

269 demonstrated that lignocellulosic structural changes are intensified with the application

270 of shearing forces using mesh gratings of coarse steel (Tsapekos et al., 2015).

271 Additionally, the pretreatment unit was always operated at one rotating speed ( $\sim 400$

$272 \mathrm{rpm}$ ) as the first BMP test showed that the enhancement of anaerobic biodegradability is

273 not directly connected with roller's rotating speed. The results from AD trials showed

274 that the modified pretreatment machine improved the process performance compared to

275 the initial model, as the biogas production was significantly enhanced $(p<0.05)$ in the 
range of $22-27 \%$ (Table 2; Fig. 2b). Moreover, it was found that the variation in the

277 biomass loadings did not have any significant effect $(p>0.05)$ on the biodegradability

278 (e.g. increase of $\mathrm{CH}_{4}$ yield, decrease of lag phase). Interesting results were obtained

279 regarding the differences on methane production rate. More specifically, at the lowest

280 (i.e. T2_a) and highest (i.e. T2_e) biomass loads the $R_{\max }$ values were slightly lower

281 compared to the untreated samples. Indeed, the positive effect of T2_a and T2_e on

282 methanation was detected after 12 and 10 days of incubation, respectively. On the

contrary, T2_b-T2_d showed an immediate positive effect on methanation since the first

284 days of AD (Table 2; Fig. 2b). Overall, a direct correlation between biomass load and

285 kinetic parameters cannot be drawn.

286 These observations are particularly important as at real grass fields the biomass

287 yield does not have a constant value but considerably varies due to heterogeneity of

288 growth stages, species etc. (Kreuger et al., 2011; Molinuevo-Salces et al., 2013). Hence,

289 intense vegetation is detected at meadows and marginal lands that can markedly

290 eliminate the cutting capacity of harvesters. Interestingly, the obtained results revealed

291 that pretreatment's efficiency was not deteriorated by increasing the amount of loaded

292 biomass. Thus, similar levels of efficiency could be achieved under non-controlled

293 conditions (i.e. real-life applications) and not only under optimized conditions (i.e. lab-

294 scale tests) in which limited amount of biomass is processed per trial. In addition, the

295 ability of pretreatment units to create structural damages on the biomass morphology

296 was revealed by the SEM analysis (Fig. 3). In this context, the efficiency of plastic

297 brush roller to peel the grass surface and increase the biodegradable area for the

298 microbial attack was revealed (Fig. 3b). Regarding the effect of the modified unit on the

299 structural changes, an increased number of small grass particles were observed due to 
the usage of coarse metal materials (Fig. 3c).

301 Focusing on full-scale applications, harvester equipped with similar apparatus that

302 apply shearing forces managed to pretreat efficiently lignocellulosic biomass and

303 consequently, could improve the methane yield up to 20\% (Tsapekos et al., 2017a).

304 Although different levels of methane yield enhancement by mechanical pretreatment

305 methods have been reported (from 8.5 to $62 \%$ ); it can be noticed that in general, the

306 impact of applied pretreatments have positive impact on substrate's biodegradability

307 (Rodriguez et al., 2016). In addition, the suitability of full-scale comminution machines

308 on improving the energy budget of grass-based AD was previously proved (Tsapekos et

309 al., 2017b). In the mentioned study, the produced biogas (output) was compared with

310 machine's energy consumption (input) and the analysis showed that a highly efficient

311 full-scale machine is able to improve the overall sustainability of grass based-AD. The

312 mechanical pretreatment methods pose the characteristics for environmentally friendly

313 management implications of waste and residues. To sum up, both applied pretreatment

314 units could induce structure damage, by presumably increasing surface area and thus,

315 improving the access of AD microorganisms to the degradable organic matter (Tedesco

316 et al., 2014).

317

\subsection{Correlation between BMP and chemical composition}

319 Results obtained from the chemical characterization of the examined lignocellulosic 320 substrates and their corresponding BMPs are summarized in Table 1. The BMP values

321 were normally distributed and represented a wide range in methane yields (i.e. from 34

322 to $524 \mathrm{~mL} / \mathrm{gVS}$ ). In fact, datasets with wide range of values are appropriate for linking

323 the chemical components and BMP values of lignocellulosic substrates (Dandikas et al., 
324 2018; Raju et al., 2011). Regarding the examined variables, only C:N ratios were not

325 normally distributed and thus, were not suitable parameters for mathematical regression 326 analyses.

327 Initially, PCA was applied to datasets (i.e. content of glucan, xylan, arabinan, lignin 328 and protein) in order to reveal the correlations among the variables. The PCA biplot 329 shows that the first two principal components explained $91 \%$ of total variation (Fig. 4).

330 Taking into account the contents of lignin, xylan, glucan, arabinan and protein, the 331 variations explained by PC1 (reflecting the linear combination of $\mathrm{x}$-variables that has

332 the highest variance) and PC2 (reflecting the linear combination of x-variables

333 accounting for the potential highest remaining variations) were $49 \%$ and $42 \%$,

334 respectively. All variables defined to be away from centre and close to the surrounding 335 circular area, indicating that samples variation was considerably explained (Fig. 4).

336 Hence, they were used to investigate possible correlations between the parameters.

337 Among variables, lignin and protein were highly inversely correlated ( $r=-0.87$, angle

338 close to $\left.180^{\circ}\right)$ and on the other hand, lignin and glucan were highly independent $(\mathrm{r}=$

3390.04 , angle $\sim 90^{\circ}$ ) (Table 3; Fig. 4). Regarding the link between chemical components

340 and methane yield, lignin polymer revealed the closest relationship $(r=-0.71, p>$

$3410.0001)$ (Table 1). The observed negative correlation is in accordance with previous

342 studies that used lignin as regressor to predict the biodegradability of lignocellulosic

343 substrates (Campuzano and Gonzalez-Martinez, 2016; Dandikas et al., 2014; Edwiges et

344 al., 2018; Herrmann et al., 2016). Single linear regression was established using lignin

345 but the calibration statistics were relatively low $\left(R^{2}=0.50, \mathrm{RMSE}=75 \mathrm{~mL} / \mathrm{gVS}\right.$,

346 NRMSE $=15 \%$ ). The model is described by equation 1 :

$$
\mathrm{CH}_{4} \text { yield }=512.44-6.69 \times \text { Lignin }
$$


where, $\mathrm{CH}_{4}$ yield is given in $\mathrm{mL} / \mathrm{gVS}$ and lignin in $\mathrm{g} / 100 \mathrm{gVS}$.

348 Previous studies concluded that simple linear regression analysis using the chemical 349 characteristics of substrates cannot lead in high estimation accuracy, but can be used as 350 an initial and time-effective prediction approach (Dandikas et al., 2014; Edwiges et al., 351 2018; Lesteur et al., 2010). However, the prediction accuracy could be improved by applying multiple linear regression models (Kafle and Chen, 2016). Hence, a multiple regression test was performed using the contents of arabinan, lignin and protein as regressors and $\mathrm{CH}_{4}$ yield as regressand. According to the PCA analysis, glucan and xylan units were insignificant for the model $(p<0.05)$ and thus, were not further used. Furthermore, outliers were not detected, as the square root of the ratio using the residual value per observation and the average residual variance was always lower than 3.0 (Dandikas et al., 2015). The analysis showed that the prediction accuracy was improved, as the $R^{2}$ of the model was 0.61 , the RMSE was $68 \mathrm{~mL} / \mathrm{gVS}$ and the NRMSE was $14 \%$.

360 The Kolmogorov-Smirnov test was applied to examine the normal distribution of the

361 residuals and the null hypothesis could not be rejected. The model is described by

362 equation 2 :

$\mathrm{CH}_{4}$ yield $=270.74+16.61 \times$ Arabinan $-3.35 \times$ Lignin $+27.88 \times$ Proteins

363 where, $\mathrm{CH}_{4}$ yield is given in $\mathrm{mL} / \mathrm{gVS}$ and the chemical compounds in $\mathrm{g} / 100 \mathrm{gVS}$.

364 Linking the chemical composition of lignocellulosic biomass and BMP values was 365 previously assessed using similar variables (Dandikas et al., 2015). Specifically, the 366 usage of protein, lignin and hemicellulose as independent variables resulted in multiple

367 linear regression model with a relatively good accuracy $\left(R^{2}=0.70\right)$. The better

368 prediction accuracy compared to the present study can be attributed to the large number

369 of grass species that were harvested at different growth stages. Therefore, better 
370 estimation accuracy was achieved due to the higher variation in significant parameters

371 (e.g. lignin content). In another study the researchers used similar regressors (i.e. lignin

372 and protein) in addition to two alternative components (i.e. butyric acid and alcohols),

373 achieving prediction accuracy $\left(R^{2}=0.64, \mathrm{RMSE}=27 \mathrm{~mL} / \mathrm{gVS}\right)$ comparable to the

374 present work (Herrmann et al., 2016). The slightly improved calibration statistics,

375 obtained in the study of (Herrmann et al., 2016), can be ascribed to the usage of a huge

376 dataset containing various silages (405 samples of 35 crop species). Hence, a very

377 heterogeneous dataset with a broad range of values was utilized that positively affects

378 the prediction accuracy (Lesteur et al., 2010). Apart from the number of samples, the

379 type of the lignocellulosic materials used in previous and current study differs also

380 markedly. Specifically, in the work of Herrmann et al. only silages were used and thus,

381 the silage fermentation products were used as regressors (Herrmann et al., 2016). In

382 contrast, the current research examined diverse lignocellulosic samples (i.e. silage,

383 fresh, straw and digested) containing a wider variety of chemical components. Thus, the

384 silage fermentation products would have extremely limited applicability in our study as

385 the majority of examined lignocellulosic samples contain limited or negligible

386 concentration of these intermediates. Overall, the chemical composition of a substrate

387 can give important information regarding its optimal methane potential and additionally,

388 this information can be used as early indicators for substrate's biodegradability.

389 However, parameters that were not considered in this study (e.g. crystallinity,

390 polymerization degree, content of monolignols p-coumaryl, coniferyl and sinapyl

391 alcohols) can be also responsible for the low prediction accuracy. Nevertheless, findings

392 from the present case study and literature conclude that the chemical synthesis of

393 lignocellulosic substrates can give relatively moderate estimation of anaerobic 
394 biodegradation. Hence, it is still extremely difficult to find efficient and alternative

395 methods to rapidly define the ultimate biodegradability of complex materials.

396

\section{Conclusions}

The application of two mechanical pretreatment units revealed to affect positively the methane yield and lag phase of grass-based anaerobic digestion process. The most aggressive machine enhanced the methane yield of meadow grass up to $27 \%$ compared to untreated samples. Moreover, the performance of the amended pretreatment unit was not negatively affected by treating increased biomass loads. Single and multiple linear regressions models were built to predict the methane production of diverse

404 lignocellulosic substrates. Moderate correlation was noted $\left(R^{2}=0.61\right)$ using arabinan, lignin and protein as independent variables. The increased complexity of lignocellulosic polymer is the major impediment to achieve high prediction accuracy using mathematical regression analyses.

\section{Acknowledgement}

410 We acknowledge financial support from EUDP project "New technology for an

411 efficient utilization of meadow grass in biogas reactor'”

\section{References}

414 Angelidaki, I., Alves, M., Bolzonella, D., Borzacconi, L., Campos, J.L., Guwy, A.J., 415 Kalyuzhnyi, S., Jenicek, P., van Lier, J.B., 2009. Defining the biomethane potential 416 (BMP) of solid organic wastes and energy crops: a proposed protocol for batch 417 assays. Water Science \& Technology 59, 927.

418 APHA, 2005. Standard Methods for the Examination of Water and Wastewater. 419 American Public Health Association, Washington, DC, USA.

420 Boscaro, D., Pezzuolo, A., Grigolato, S., Cavalli, R., Marinello, F., Sartori, L., 2015. 
Preliminary analysis on mowing and harvesting grass along riverbanks for the supply of anaerobic digestion plants in north-eastern Italy. Journal of Agricultural Engineering 46, 100-104.

Campuzano, R., Gonzalez-Martinez, S., 2016. Characteristics of the organic fraction of municipal solid waste and methane production: A review. Waste Management 54, $3-12$.

Carrere, H., Antonopoulou, G., Affes, R., Passos, F., Battimelli, A., Lyberatos, G., Ferrer, I., 2015. Review of feedstock pretreatment strategies for improved anaerobic digestion: From lab-scale research to full-scale application. Bioresource Technology 199, 386-397.

Charnier, C., Latrille, E., Jimenez, J., Lemoine, M., Boulet, J.-C., Miroux, J., Steyer, J.P., 2016. Fast characterization of solid organic waste content with near infrared spectroscopy in anaerobic digestion. Waste Management 59, 140-148.

Dandikas, V., Heuwinkel, H., Lichti, F., Drewes, J.E., Koch, K., 2014. Correlation between biogas yield and chemical composition of energy crops. Bioresource technology 174, 316-20.

Dandikas, V., Heuwinkel, H., Lichti, F., Drewes, J.E., Koch, K., 2015. Correlation between biogas yield and chemical composition of Grassland Plant Species. Energy \& Fuels 29, 7221-7229.

Dandikas, V., Heuwinkel, H., Lichti, F., Eckl, T., Drewes, J.E., Koch, K., 2018. Correlation between hydrolysis rate constant and chemical composition of energy crops. Renewable Energy 118, 34-42.

Edwiges, T., Frare, L., Mayer, B., Lins, L., Mi Triolo, J., Flotats, X., de Mendonça Costa, M.S.S., 2018. Influence of chemical composition on biochemical methane potential of fruit and vegetable waste. Waste Management 71, 618-625.

Faostat, 2016. Food and Agriculture Organization of the United Nations - Statistical Databases [WWW Document]. URL http://faostat.fao.org (accessed 5.1.16).

Fitamo, T., Triolo, J.M., Boldrin, A., Scheutz, C., 2017. Rapid biochemical methane potential prediction of urban organic waste with near-infrared reflectance spectroscopy. Water Research 119, 242-251.

Frigon, J.C., Guiot, S.R., 2010. Biomethane production from starch and lignocellulosic crops: A comparative review. Biofuels, Bioproducts and Biorefining 4, 447-458.

Hayashi, K., Ono, K., Kajiura, M., Sudo, S., Yonemura, S., Fushimi, A., Saitoh, K., Fujitani, Y., Tanabe, K., 2014. Trace gas and particle emissions from open burning of three cereal crop residues: Increase in residue moistness enhances emissions of carbon monoxide, methane, and particulate organic carbon. Atmospheric Environment 95, 36-44.

Herrmann, C., Idler, C., Heiermann, M., 2016. Biogas crops grown in energy crop rotations: Linking chemical composition and methane production characteristics. 
Herrmann, C., Prochnow, A., Heiermann, M., Idler, C., 2012. Particle Size Reduction

462

463

464

465

466

467

468

469

470

471

472

473

474

475

476

477

478

479

480

481

482

483

484

485

486

487

488

489

490

491

492

493

494

495

496

497

498
During Harvesting of Crop Feedstock for Biogas Production II: Effects on Energy Balance, Greenhouse Gas Emissions and Profitability. Bioenergy Research 5, $937-$ 948.

Kafle, G.K., Chen, L., 2016. Comparison on batch anaerobic digestion of five different livestock manures and prediction of biochemical methane potential (BMP) using different statistical models. Waste Management 48, 492-502.

Katukuri, N.R., Fu, S., He, S., Xu, X., Yuan, X., Yang, Z., Guo, R.-B., 2017. Enhanced methane production of Miscanthus floridulus by hydrogen peroxide pretreatment. Fuel 199, 562-566.

Kougias, P.G., Boe, K., Einarsdottir, E.S., Angelidaki, I., 2015. Counteracting foaming caused by lipids or proteins in biogas reactors using rapeseed oil or oleic acid as antifoaming agents. Water Research 79, 119-127.

Kratky, L., Jirout, T., 2011. Biomass Size Reduction Machines for Enhancing Biogas Production. Chemical Engineering \& Technology 34, 391-399.

Kreuger, E., Prade, T., Escobar, F., Svensson, S.-E., Englund, J.-E., Björnsson, L., 2011. Anaerobic digestion of industrial hemp-Effect of harvest time on methane energy yield per hectare. Biomass and Bioenergy 35, 893-900.

Lesteur, M., Bellon-Maurel, V., Gonzalez, C., Latrille, E., Roger, J.M., Junqua, G., Steyer, J.P., 2010. Alternative methods for determining anaerobic biodegradability: A review. Process Biochemistry 45, 431-440.

Marañón, E., Salter, A.M., Castrillón, L., Heaven, S., Fernández-Nava, Y., 2011. Reducing the environmental impact of methane emissions from dairy farms by anaerobic digestion of cattle waste. Waste Management 31, 1745-1751.

Molinuevo-Salces, B., Larsen, S.U., Ahring, B.K., Uellendahl, H., 2013. Biogas production from catch crops: Evaluation of biomass yield and methane potential of catch crops in organic crop rotations. Biomass and Bioenergy 59, 285-292.

Mönch-Tegeder, M., Lemmer, A., Oechsner, H., 2014. Enhancement of methane production with horse manure supplement and pretreatment in a full-scale biogas process. Energy 73, 523-530.

Raju, C.S., Ward, A.J., Nielsen, L., Møller, H.B., 2011. Comparison of near infra-red spectroscopy, neutral detergent fibre assay and in-vitro organic matter digestibility assay for rapid determination of the biochemical methane potential of meadow grasses. Bioresource Technology 102, 7835-7839.

Ranjan, A., Moholkar, V.S., 2013. Comparative study of various pretreatment techniques for rice straw saccharification for the production of alcoholic biofuels. Fuel 112, 567-571.

Rodriguez, C., Alaswad, A., Benyounis, K.Y., Olabi, A.G., 2016. Pretreatment 
techniques used in biogas production from grass. Renewable and Sustainable Energy Reviews 1-12.

Sluiter, A., Hames, B., Ruiz, R., Scarlata, C., Sluiter, J., Templeton, D., Crocker, D., 2011. Determination of Structural Carbohydrates and Lignin in Biomass. Golden, CO.

Tedesco, S., Mac Lochlainn, D., Olabi, A.G., 2014. Particle size reduction optimization of Laminaria spp. biomass for enhanced methane production. Energy 76, 857-862.

Triolo, J.M., Sommer, S.G., Møller, H.B., Weisbjerg, M.R., Jiang, X.Y., 2011. A new algorithm to characterize biodegradability of biomass during anaerobic digestion: influence of lignin concentration on methane production potential. Bioresource technology 102, 9395-402.

Tsapekos, P., Kougias, P.G., Angelidaki, I., 2015. Biogas production from ensiled meadow grass; effect of mechanical pretreatments and rapid determination of substrate biodegradability via physicochemical methods. Bioresource Technology 182, 329-335.

Tsapekos, P., Kougias, P.G., Egelund, H., Larsen, U., Pedersen, J., Trénel, P., Angelidaki, I., 2017a. Mechanical pretreatment at harvesting increases the bioenergy output from marginal land grasses. Renewable Energy 111, 914-921.

Tsapekos, P., Kougias, P.G., Egelund, H., Larsen, U., Pedersen, J., Trénel, P., Angelidaki, I., 2017b. Improving the energy balance of grass-based anaerobic digestion through harvesting optimisation. Anaerobe 46, 131-137.

Vervaeren, H., Hostyn, K., Ghekiere, G., Willems, B., 2010. Biological ensilage additives as pretreatment for maize to increase the biogas production. Renewable Energy 35, 2089-2093.

Wang, H., Lehtomäki, A., Tolvanen, K., Puhakka, J., Rintala, J., 2009. Impact of crop species on bacterial community structure during anaerobic co-digestion of crops and cow manure. Bioresource Technology 100, 2311-2315. 
527 Figure captions

528 Fig. 1. Comminuting machines used for the mechanical pretreatment of grass.

529

530 Fig. 2. Accumulated methane yields of untreated and mechanically pretreated grass.

531

532 Fig. 3. SEM images of meadow grass particles untreated (a) and pretreated with the

533 initial (b) and modified (c) pretreatment unit

534

535 Fig. 4. Correlation loadings plot for the first principal component (PC1) versus the 536 second principal component (PC2) of structural polymers.

537 
539 Table 1. Chemical composition and methane yield of used lignocellulosic substrates

\begin{tabular}{|c|c|c|c|c|c|c|c|}
\hline & $\begin{array}{c}\text { Glucan, } \\
\% \mathrm{VS}\end{array}$ & $\begin{array}{l}\text { Xylan, } \\
\% \text { VS }\end{array}$ & $\begin{array}{c}\text { Arabinan, } \\
\% \mathrm{VS}\end{array}$ & $\begin{array}{c}\text { Lignin, } \\
\% \mathrm{VS}\end{array}$ & $\begin{array}{c}\text { Protein, } \\
\% \text { VS }\end{array}$ & $\begin{array}{l}\mathrm{C}: \mathrm{N} \\
\text { ratio }\end{array}$ & $\begin{array}{c}\mathrm{CH}_{4} \text { yield, } \\
\mathrm{mL} / \mathrm{gVS}\end{array}$ \\
\hline M1 & $48 \pm 2$ & $24 \pm 1$ & $6 \pm 0$ & $20 \pm 1$ & $3 \pm 0$ & $24 \pm 1$ & $474 \pm 50$ \\
\hline M2 & $37 \pm 3$ & $24 \pm 1$ & $4 \pm 0$ & $41 \pm 0$ & $2 \pm 0$ & $21 \pm 1$ & $317 \pm 12$ \\
\hline M3 & $36 \pm 1$ & $22 \pm 1$ & $4 \pm 0$ & $37 \pm 2$ & $2 \pm 0$ & $25 \pm 0$ & $307 \pm 25$ \\
\hline M4 & $37 \pm 0$ & $21 \pm 0$ & $4 \pm 0$ & $36 \pm 1$ & $2 \pm 0$ & $23 \pm 0$ & $305 \pm 15$ \\
\hline M5 & $40 \pm 0$ & $24 \pm 0$ & $5 \pm 0$ & $29 \pm 0$ & $2 \pm 0$ & $24 \pm 1$ & $292 \pm 15$ \\
\hline M6 & $49 \pm 2$ & $20 \pm 1$ & $5 \pm 1$ & $25 \pm 0$ & $2 \pm 0$ & $19 \pm 1$ & $292 \pm 23$ \\
\hline M7 & $42 \pm 1$ & $29 \pm 1$ & $5 \pm 1$ & $23 \pm 1$ & $1 \pm 0$ & $25 \pm 1$ & $299 \pm 35$ \\
\hline GC & $54 \pm 4$ & $21 \pm 2$ & $7 \pm 1$ & $15 \pm 5$ & $3 \pm 0$ & $14 \pm 0$ & $326 \pm 43$ \\
\hline WS & $40 \pm 2$ & $27 \pm 1$ & $3 \pm 0$ & $30 \pm 3$ & $0 \pm 0$ & $103 \pm 5$ & $255 \pm 17$ \\
\hline DB & $34 \pm 0$ & $17 \pm 0$ & $1 \pm 0$ & $47 \pm 0$ & $1 \pm 0$ & $45 \pm 2$ & $42 \pm 8$ \\
\hline MIN & 33.5 & 16.4 & 1.1 & 9.6 & 0.2 & 13.3 & 33.9 \\
\hline MAX & 58.6 & 29.4 & 7.2 & 47.7 & 3.3 & 108.5 & 524.2 \\
\hline MEAN & 41.4 & 22.5 & 4.3 & 30.0 & 1.7 & 32.2 & 290.8 \\
\hline SDTEV & 6.5 & 3.5 & 1.6 & 9.4 & 0.8 & 25.3 & 104.0 \\
\hline $\mathrm{CV}$ & $16 \%$ & $15 \%$ & $38 \%$ & $31 \%$ & $48 \%$ & $79 \%$ & $36 \%$ \\
\hline
\end{tabular}

M1-M7: meadow grass; GC: grass clippings; WS: wheat straw; DB: digested biofibers

SDTEV: standard deviation; CV: coefficient of variation 
541 Table 2. Effects of mechanically pretreatments and summary of kinetic study

Road sweeping brush against crimper

\begin{tabular}{cccccccc}
\hline & $\begin{array}{c}\text { Brush, } \\
\text { rpm }\end{array}$ & $\begin{array}{c}\text { Crimper, } \\
\mathbf{r p m}\end{array}$ & $\begin{array}{c}\mathbf{C H} \text { yield, } \\
\mathbf{m L} / \mathbf{g V S}\end{array}$ & $\begin{array}{c}\boldsymbol{R}_{\max }, \\
\mathbf{m L} / \mathbf{g V S} / \mathbf{d}\end{array}$ & $\begin{array}{c}\lambda, \\
\mathbf{d}\end{array}$ & $\boldsymbol{R}^{\mathbf{2}}$ & $\mathbf{R M S E}$ \\
\hline T1_0 & - & - & $305 \pm 36$ & 30 & 3.35 & 0.999 & 3.43 \\
T1_a & 200 & 1200 & $341 \pm 21$ & 34 & 3.17 & 0.999 & 4.57 \\
T1_b & 600 & 1200 & $367 \pm 27$ & 31 & 2.69 & 0.995 & 8.90 \\
T1_c & 900 & 1200 & $344 \pm 10$ & 30 & 2.82 & 0.997 & 6.82 \\
T1_d & 1200 & 1200 & $345 \pm 11$ & 31 & 3.29 & 0.998 & 5.97 \\
\hline
\end{tabular}

2nd test Stable coarse shell against rotated corrugated roller $(\sim 400 \mathbf{r p m})$

\begin{tabular}{ccccccc}
\hline & $\begin{array}{c}\text { Biomass load, } \\
\text { kg grass/m }\end{array}$ & $\begin{array}{c}\text { CH4 yield, } \\
\mathbf{m L} / \mathbf{g V S}\end{array}$ & $\begin{array}{c}\boldsymbol{R}_{\text {max }}, \\
\mathbf{m L} / \mathbf{g V S} / \mathbf{d}\end{array}$ & $\begin{array}{c}\boldsymbol{\lambda}, \\
\mathbf{d}\end{array}$ & $\boldsymbol{R}^{\mathbf{2}}$ & $\mathbf{R M S E}$ \\
\hline T2_0 & - & $297 \pm 21$ & 31 & 2.10 & 0.981 & 14.67 \\
T2_a & 1.40 & $364 \pm 20$ & 26 & 1.85 & 0.988 & 14.68 \\
T2_b & 1.05 & $371 \pm 20$ & 44 & 1.83 & 0.999 & 4.22 \\
T2_c & 0.80 & $371 \pm 18$ & 39 & 1.20 & 0.989 & 14.01 \\
T2_d & 0.60 & $361 \pm 14$ & 35 & 1.74 & 0.996 & 8.10 \\
T2_e & 0.40 & $376 \pm 28$ & 27 & 1.53 & 0.994 & 10.60 \\
\hline
\end{tabular}

T1_0 and T2_0: Untreated samples at the first and second test, respectively

T1_a - T1_d and T2_a - T1_e: Mechanically pretreated samples at the first and second test, respectively $R_{\text {max }}$ : maximum $\mathrm{CH}_{4}$ production rate; $\lambda$ : lag phase; $R^{2}$ : coefficient of determination; RMSE: root mean square error 
543 Table 3. Pearson's correlation coefficients of chemical compounds and methane yield

544 of all lignocellulosic samples

\begin{tabular}{lcccccc}
\hline Variables & Glucan & Xylan & Arabinan & Lignin & Protein & CH4 yield $^{\text {Gran }}$ \\
\hline Glucan & 0.76 & 0.54 & 0.04 & -0.24 & 0.04 \\
Xylan & & 1 & 0.36 & 0.32 & -0.54 & 0.01 \\
Arabinan & & & 1 & -0.57 & 0.46 & 0.56 \\
Lignin & & & & 1 & -0.87 & -0.71 \\
Protein & & & & & 1 & 0.62 \\
CH4 yield & & & & & & 1 \\
\hline
\end{tabular}

